\title{
EL DERECHO A SER INFORMADO DE LA ACUSACIÓN EN LA JURISPRUDENCIA DEL TRIBUNAL EUROPEO DE DERECHOS HUMANOS Y DEL TRIBUNAL CONSTITUCIONAL ESPAÑOL
}

\author{
MIGUEL AGUDO ZAMORA \\ Profesor Titular de Derecho Constitucional \\ Universidad de Córdoba \\ CIRO MILIONE \\ Investigador \\ Universidad de Córdoba
}
SUMARIO
I. El artículo 10.2 de la Constitución espa- ñola.
II. Algunas consideraciones acerca de las ca- racterísticas principales del art. 6 del Con- venio Europeo de Derechos Humanos.
III. El derecho a ser informado de la acusa- ción en la jurisprudencia del TEDH.
IV. El derecho a ser informado de la acusa- ción en la jurisprudencia del TC.
V. Conclusiones.

\section{EL ARTÍCULO 10.2 DE LA CONSTITUCIÓN ESPAÑOLA}

La importancia de los derechos fundamentales ${ }^{1}$ para un Estado de Derecho queda reflejada en nuestra Constitución, desde el primer párrafo del art. 10, donde se establece que "la dignidad de la persona, los derechos inviolables que le son inherentes, el libre desarrollo de la personalidad, el respeto a la ley y a los derechos de los demás son fundamento del orden político y de la paz social..

1 L. M. Diez-Picazo, Sistema de derechos fundamentales, Civitas, Madrid, 2003. 
Existe, pues, entonces un estrecho nexo de interdependencia genético y funcional entre el Estado de Derecho y los derechos fundamentales, pues mientras el primero exige, y a la vez implica para serlo, garantizar los derechos fundamentales, éstos últimos exigen e implican para su realización al Estado de Derecho².

Asimismo, la menor o mayor amplitud del reconocimiento constitucional de los derechos, así como su protección y garantías, constituyen un parámetro suficientemente fiable para medir la legitimidad democrática del orden político de un Estado ${ }^{3}$.

En la Constitución española, estos derechos y libertades no sólo disfrutan de una serie de garantías a la hora de su desarrollo y protección ${ }^{4}$ sino que además a la hora de su interpretación, es de constante aplicación el principio hermenéutico del favor libertatis, por el que los derechos deben interpretarse del modo más amplio posible, de la forma más favorable para su efectividad. Igualmente es de indudable aplicación otro principio que la Constitución incluye en el sistema jurídico: el principio por el que la interpretación de los derechos ha de ser conforme con los Tratados Internacionales sobre derechos humanos ratificados por España (art. 10.2 CE)

Según pone en evidencia el mismo Tribunal Constitucional ${ }^{6}$ la Constitución es hija de un periodo caracterizado por la apertura del constitucionalismo a los fenómenos de cooperación e integración internacional, entre los que cabe incluir los derechos fundamentales y libertades públicas.

En este sentido, se entiende la gran importancia que adquiere este precepto, por el que, según entiende un amplio sector de la doctrina ${ }^{7}$, "el apar-

2 A. PÉrez LuÑo, Los derechos fundamentales, Tecnos, Madrid, 1991, p. 19.

3 M. J. Agudo Zamora, El Tribunal Constitucional y el Convenio Europeo de Derechos Humanos, Universidad de Córdoba, Servicio de Publicaciones, Córdoba, 2001, p. 15.

4 Pensemos en el hecho de que los derechos fundamentales vinculan a todos los poderes públicos, por lo que son de aplicación directa; la regulación de su ejercicio sólo puede hacerse mediante Ley (art. 53.1 CE) que ostenta la naturaleza y requisitos de Orgánica cuando se trata del desarrollo de derechos fundamentales y libertades públicas (art. 81.1), respetando siempre su "contenido esencial" (art. 53.1 CE). Además de esto, debido a su importante valor axiológico, los artículos que contienen estos derechos y libertades fundamentales necesitan, para su reforma, del procedimiento agravado (art. $168 \mathrm{CE}$ ), y, finalmente, disfrutan de unos mecanismos específicos de tutela para los casos concretos en que se puedan considerar vulnerados: el amparo judicial preferente y sumario y el recurso de amparo ante el Tribunal Constitucional (art. 53.2 CE).

5 A. SÁIZ ARNAIZ, "La apertura constitucional al Derecho internacional y europeo de los derechos humanos. El Art. 10.2 de la Constitución Española", Consejo General del Poder Judicial, Madrid, 1999. Sobre el mismo argumento recordamos también, F. DE CARRERAS SERRA, "Función y alcance del artículo 10.2 de la Constitución", en Revista española de derecho constitucional, año n. 20, n. 60, 2000, pp. 321-342; M. A. APARICIO PÉREZ, "La cláusula interpretativa del artículo 10.2 de la Constitución española, como cláusula de integración y apertura constitucional a los derechos fundamentales", en Jueces para la Democracia, n. 6, 1989.

6 Nos referimos a la STC 62/1982, de 15 de octubre.

7 A. Mangas Martín, "Cuestiones de Derecho Internacional Público en la Constitución Española de 1978", en Revista de la Facultad de Derecho de la Universidad Complutense, n. 61, 1980, p. 150 . 
tado segundo del art. 10 no apela a los convenios internacionales en cuanto Derecho interno, sino que la referencia explicita a la Declaración Universal de Derechos Humanos y a otros acuerdos internacionales sobre dicha materia se hace sólo a efectos de interpretación de los derechos y libertades incluidos en la Constitución", por lo que realmente este precepto no introduce una constitucionalización de los acuerdos internacionales sobre derechos humanos, sino un puro criterio interpretativo ${ }^{8}$.

Sin embargo, es otra norma la que se encarga de disciplinar la introducción en el sistema jurídico interno de los tratados internacionales, el art. 96 de la Constitución, por el que "los tratados internacionales válidamente celebrados, una vez publicados oficialmente en España, formarán parte del ordenamiento interno".

Así, mientras este precepto desarrolla la función de cauce a través del cual el Derecho Internacional se hace Derecho interno, el art. 10.2 CE desarrolla otro papel, el de cláusula de garantía, puesto que todas las dificultades interpretativas, relativas a derechos fundamentales y libertades políticas deben resolverse a favor de la interpretación suministrada por los tratados ratificados 9 . De esta manera, aunque lo que se integra en nuestro ordenamiento es el texto integro del tratado (según lo establecido por el art. $96 \mathrm{CE}$ ), es mediante el art 10.2 CE que la protección de los derechos humanos alcanza a la interpretación que sobre tales derechos haya podido hacer, por ejemplo, el Tribunal Europeo de Derechos Humanos o el Tribunal de Justicia de las Comunidades Europeas ${ }^{10}$.

La consideración de que a través de la técnica interpretativa impuesta por el art. 10.2 CE, igualmente, se permite la incorporación al acervo legislativo y jurisprudencial de nuevos derechos, no sólo cívicos y políticos, sino también económicos, sociales y culturales, sirve para acrecentar la importancia de esta misma norma constitucional.

El carácter preceptivo del art. 10.2 CE está claramente descrito por Mangas Martín ${ }^{11}$ cuando considera que los tratados internacionales se dirigen también al Legislativo y a la Administración, de tal forma que no pueden aprobarse leyes o disposiciones que choquen con los tratados mismos o que vayan en contra de los criterios interpretativos emanados por los órganos jurisprudenciales previstos en los convenios internacionales; en caso contrario se incurriría en un caso de patente inconstitucionalidad.

Es interesante poner en evidencia que la interpretación a la que alude el art. 10.2 CE es una interpretación in bonum, es decir, capaz de ampliar el

8 En particular, M. J. Agudo ZAMORA, "La interpretación de los derechos y libertades constitucionales a través de los Tratados Internacionales: La técnica del artículo 10.2", en Estudios Penales y Juridicos. Homenaje al Prof. Dr. Enrique Casas Barquero (coord. por Juan José GonzÁLEZ Rus), Córdoba, 1996, pp. 38-40.

9 A. MANGas, op. cit., p. 150.

10 J. Ruiz-Giménez Cortés, "Artículo 10. Derechos fundamentales de la persona", en la obra colectiva Comentarios a las leyes politicas. Constitución española de 1978, vol. II, p. 137.

11 A. Mangas, op. cit., p. 152 y ss. 
contenido y ejercicio del derecho en cuestión, no pudiendo, por tanto, restringirlo en ningún momento.

Hay que tener en cuenta, por otra parte, lo establecido en el art. 60 del Convenio Europeo de Derechos Humanos, cuando se afirma que "ninguna de las disposiciones del presente Convenio será interpretada en el sentido de limitar y perjudicar aquellos derechos bumanos y libertades fundamentales que podrian ser reconocidos conforme a las leyes de cualquier Alta Parte Contratante o en cualquier otro Convenio en el que ésta sea parte".

Así, pues, no podemos dejar de respaldar la opinión de Liñán Nogueras ${ }^{12}$, según la cual los tratados internacionales representan normas con carácter de "mínimos", por lo que compete a la legislación interna incrementar, a través de normas de aplicación y a la jurisprudencia de los Tribunales, el estándar de protección establecido en ellos.

Concluyendo, vemos cómo, en definitiva, se debe principalmente al art. 10.2 CE la exigencia, por parte de los órganos legislativos y de gobierno, así como también por los órganos jurisdiccionales, de llevar a cabo una actividad de interpretación de los tratados internacionales en un sentido favorable al ejercicio y a la amplitud de los derechos fundamentales y de las libertades políticas.

\section{ALGUNAS CONSIDERACIONES ACERCA DE LAS CARACTERÍSTICAS PRINCIPALES DEL ART. 6 DEL CONVENIO EUROPEO DE DERECHOS HUMANOS}

El art. $6^{13}$ del Convenio Europeo de Derechos Humanos (a partir de ahora CEDH o más sencillamente Convenio) puede ser considerado como un

12 D. LiÑán Nogueras, Efectos de las Sentencia del Tribunal Europeo de Derechos Humanos y Derecho Español, en REDI, vol. XXXVII 1985/2, p. 367.

13 Art. 6 del CEDH: "Toda persona tiene derecho a que su causa sea oída de manera equitativa, públicamente y dentro de un plazo razonable, por un tribunal independiente e imparcial, establecido por la ley, que decidirá de los litigios sobre sus derechos y obligaciones de carácter civil o sobre el fundamento de cualquier acusación en materia penal dirigida contra ella. La sentencia debe ser pronunciada públicamente, pero el acceso a la sala de audiencia puede ser probibido a la prensa y al público durante la totalidad o parte del proceso en interés de la moralidad, del orden público o de la seguridad nacional en una sociedad democrática, cuando los intereses de los menores o la protección de la vida privada de las partes en el proceso así lo exijan o en la medida en que sea considerado estrictamente necesario por el tribunal, cuando en circunstancias especiales la publicidad pudiera ser perjudicial para los intereses de la justicia". Toda persona acusada de una infracción se presume inocente hasta que su culpabilidad haya sido legalmente declarada. Todo acusado tiene, como minimo, los siguientes derechos: a) a ser informado, en el más breve plazo, en una lengua que comprenda y detalladamente, de la naturaleza y de la causa de la acusación formulada contra él; b) a disponer del tiempo y de las facilidades necesarias para la preparación de su defensa; c) a defenderse por sí mismo o a ser asistido por un defensor de su elección y, si no tiene medios para remunerarlo, poder ser asistido gratuitamente por un abogado de oficio, cuando los intereses de la justicia lo exijan; d) a interrogar o hacer interrogar a los testigos de cargo y a obtener la comparecencia e interrogatorio de los testi- 
amplio contenedor de garantías y de situaciones jurídicas subjetivas dirigidas a un ámbito definido de aplicación: el contexto procesal, en todas sus vertientes.

En este sentido, esta norma exige, por parte de los Estados contratantes, el reconocimiento y la realización de un extenso abanico de derechos, que, en sí mismos, concretan la efectividad del derecho a la tutela judicial.

Según pone en evidencia Agudo Zamora ${ }^{14}$ "el contenido del derecho a la protección judicial supone no sólo el derecho al acceso los Tribunales, sino también el derecho a obtener una tutela efectiva de dichos Tribunales", por lo que los recurrentes han de ser oídos ${ }^{15}$, han de tener derecho a una decisión fundada en derecho - ya sea favorable o adversa $-{ }^{16}$, sin que, en ningún caso, pueda producirse indefensión ${ }^{17}$.

Es cierto que una de las características más relevantes de esta norma está representada por su estructura que consta, fundamentalmente, de dos partes diferenciadas ${ }^{18}$ :

- Un primer párrafo, en el que se enuncian los principios propios del proceso equitativo (el derecho a un tribunal independiente, imparcial y establecido por la ley, el principio de contradicción y de igualdad de armas, el derecho a un proceso público, el plazo razonable, la motivación de las resoluciones judiciales), principios referidos tanto al ámbito civil como penal. En este mismo apartado se circunscribe, además, el campo de aplicación del derecho a la tutela judicial efectiva.

- Los apartados segundo y tercero, en los que se reconocen diferentes garantías que proceden del más general "principio equitativo" consagrado en el párrafo primero: el derecho a no declarar contra uno mismo, el derecho a la presunción de inocencia, el derecho de defensa, el derecho a ser informado de la acusación, el derecho a interrogar a los testigos, el derecho a la asistencia de un interprete, e, incluso, el derecho al doble grado de jurisdicción.

En todo su conjunto, esta norma destaca por su preponderante referencia a unos elementos que son propios del proceso penal.

gos que declaren en su favor en las mismas condiciones que los testigos de cargo; e) a ser asistido gratuitamente por un intérprete, si no comprende o no habla la lengua empleada en la audiencia.

14 M. J. Agudo Zamora, El Tribunal Constitucional y el Convenio Europeo de Derechos Humanos, op. cit., pp. 42 y 43.

15 Sentencia del Tribunal Europeo de Derechos Humanos (a partir de ahora STEDH) de 27 de febrero de 1980, caso Deweer.

16 Que el derecho a la tutela judicial efectiva comprenda el derecho a obtener una resolución judicial fundada en Derecho supone una garantía frente a la arbitrariedad de los poderes públicos.

17 Sentencia del y Tribunal Constitucional (a partir de ahora STC) n. 24 de 14 de julio de 1981.

18 Así J. Velu y R. ERGeC, La convention européenne de dorits de l'homme, Bruselas, 1990, pp. 336 y 337. 
Esta singularidad, que podemos considerar como otra característica predominante del art. 6 del Convenio, consiste en que, frente a la igualdad del resultado perseguido — es decir, la reconstrucción de la verdad procesal—, el proceso penal parece exigir "algo más" que lo que se pretende en relación a las demás jurisdicciones.

¿Qué justificación puede legitimar tal trato diferente por parte del CEDH?

En realidad podemos distinguir, entre las peculiaridades propias del proceso penal, unos elementos subjetivos de otros objetivos, que, conjuntamente, hacen imprescindible un tratamiento ad hoc y específico para este tipo de jurisdicción.

Por un lado, pues, hay que tomar en consideración la "desigualdad estructural" propia del proceso penal, debido a la presencia y a la intervención en el mismo, no ya de un sujeto cualquiera, sino de un órgano del Estado - el Ministerio Fiscal, encargado de ejercer la acusación pública- que, generalmente, se contrapone a la defensa.

De esta manera, el legislador internacional ha considerado oportuno exigir a los Estados contratantes un despliegue superior de garantías dirigido a aquel sujeto pasivo del proceso penal —es decir, el acusado- al que se refieren tanto el párrafo primero — como simple parte de un procedimiento judicial, cualquiera que sea-como, en particular, el segundo y tercer párrafo del art. $6 \mathrm{CEDH}$, en calidad de imputado en un procedimiento penal ${ }^{19}$.

Juntas a estas consideraciones de carácter propiamente subjetivo, nos enfrentamos con otras de carácter objetivo, centradas sobre la misma estructura bipolar del juicio penal, estructura que justificaría, por sí sola, la necesidad de una mayor tutela del acusado.

Así, en la mayoría de los casos, el proceso penal se caracteriza por la existencia de un momento dedicado fundamentalmente a la investigación e instrucción de todo el procedimiento, al que sigue, como consecuencia lógica y jurídica, otra fase dirigida, exclusivamente, al enjuiciamiento.

Esta bipolaridad se traduce en una aplicación necesariamente limitada y controlada de los principios consagrados en el primer párrafo del art. 6 - en particular del principio de igualdad de armas y de contradicción-, pues las características propias de aquel primer estadio del procedimiento junto con la necesidad de asegurar la misma efectividad del proceso penal, lo exigen.

Exigencia que no afecta igualmente a la fase del enjuiciamiento en la que la aplicación de todo el conjunto de postulados contenidos en el art. 6 del Convenio vuelve a desplegarse en toda su plenitud y sin limitación alguna ${ }^{20}$.

Efectivamente, esta peculiaridad que hemos definido como una peculiaridad del CEDH y del derecho a la tutela judicial efectiva en él consagrado no

19 En este sentido se justifica la opinión del Tribunal de Estrasburgo que considera las garantías del apartado tercero del art. 6 como constitutivas de aspectos particulares o específicos de la noción de "proceso con todas las garantías" que configura el primer párrafo de la misma norma. Véase entre otros el caso Bönisch contra Austria, STEDH de 6 de mayo de 1985.

20 Véase al respecto el caso Edwards contra Reino Unido, STEDH de 16 de diciembre de 1992. 
es sino la consecuencia de la aplicación, al ámbito procesal-penal, del principio de igualdad, y contribuye a demostrar que, al menos, el principio de contradicción no llega a ser un derecho absoluto ya que, como explica el mismo Tribunal de Estrasburgo ${ }^{21}$, pueden concurrir circunstancias que, atendiendo a intereses igualmente importantes, pueden conllevar una limitación de este mismo derecho.

De esta forma, la necesidad de considerar valores fundamentales como la protección de testigos, la salvaguardia de la seguridad nacional, la necesidad de mantener el secreto sobre los métodos policiales de investigación de los delitos, provocan de manera inevitable una redefinición de los principios contenidos en el art. 6.1 del Convenio y, consecuentemente, de todas aquellas situaciones jurídico-subjetivas que puedan derivar de ellos, en primis el derecho de la defensa a disponer del material probatorio producido por la acusación.

Pero no se tratan de límites incondicionados o carentes de control o consecuencia. Como recuerda el Tribunal de Estrasburgo, en la Sentencia relativa al caso Edwards y Lewis contra Reino Unido, serán admisibles sólo aquellas limitaciones antes mencionadas y estrictamente necesarias. Además podrán ser compensadas equitativamente por los Jueces ${ }^{22}$.

Cuanto se ha ilustrado hasta este momento nos sirve para poner en evidencia otra peculiaridad del art. 6 del Convenio.

La particular atención que el legislador internacional ha querido dedicar al proceso penal respecto a las demás jurisdicciones se traduce, desde un punto de vista subjetivo o de los destinatarios de la norma, en una amplia alusión a la figura del "acusado".

Es cierto que la referencia que se hace a la defensa procede de otros principios fundamentales, como, en primer lugar, la presunción de no culpabilidad y pretende proteger a aquel sujeto que, presumido inocente hasta sentencia firme que no certifique lo contrario, se ve llamado a desarrollar una estrategia defensiva dentro de un contexto tal vez desconocido, complejo y, en parte, poco comprensible como puede ser un juicio penal.

Por ello, en el seno del art. 6.2 y 6.3 del Convenio, el "acusado" parece ser el actor principal de un escenario al que ninguno de nosotros, a priori, ambiciona llegar: el proceso penal.

Sin embargo, siguiendo con nuestra metáfora teatral, no dejan de existir y de revestir papeles igualmente relevantes otros actores, representados por las victimas del delito, los testigos o la parte civil.

El CEDH no parece dedicar ninguna atención particular a estos sujetos, pues no aparece en ningún momento referencia alguna explícita a ellos en el art. 6.

21 Caso Edwards y Lewis contra Reino Unido, STEDH de 22 de julio de 2003.

22 Con palabras del TEDH "...además, en orden a la necesidad de garantizar un proceso equitativo para el acusado, toda dificulta que pueda conocer la defensa como consecuencia de limitaciones a sus derechos debe ser suficientemente compensada en los procedimientos seguidos por las autoridades judiciales”. Véase además el caso Doorson contra Países Bajos, STEDH de 26 de marzo de 1996 y el caso Jasper contra Reino Unido, STEDH de 16 de febrero de 2000. 
A pesar de esto, es cierto que la presencia - necesaria o eventual- de estos sujetos dentro del proceso no carece de importantes consecuencias jurídicas, y se pueden considerar aplicables a ellos todas las garantías previstas, en un principio, fundamentalmente para el acusado.

Es cierto pues, que, a pesar del aparente silencio del Convenio en relación a estas partes del proceso, no se produce una absoluta indefensión de las mismas. En este sentido no podemos ni tenemos que olvidar el hecho de que el CEDH representa un importantísimo instrumento de tutela de todos los derechos fundamentales y no sólo del derecho a un proceso equitativo.

Por ello, la necesidad de proteger bienes como la vida, la libertad, e incluso la seguridad de estos sujetos que, aunque partes del proceso, no tienen el papel de "acusados", no podrá considerarse dejada al margen de las preocupaciones del Tribunal de Estrasburgo.

Por otro lado, estas consideraciones producen, como efecto, el hecho de obligar a los Estados a construir un proceso penal en el que se respete la integridad de estos derechos, de forma tal que no se vean afectados por el desarrollo de la actividad jurisdiccional penal.

Estas consideraciones nos indican finalmente que, en determinados casos, el desarrollo de un proceso con todas las garantías determinará la necesidad de buscar un equilibrio entre el interés de la defensa del acusado y el de los testigos, de las victimas y de todas aquellas partes que eventualmente estén llamadas a participar en el proceso mismo ${ }^{23}$.

Al margen de estas reflexiones, nos planteamos desarrollar un breve estudio sobre las últimas sentencias del Tribunal Constitucional que han recibido la jurisprudencia del Tribunal Europeo de Derechos Humanos (a partir de ahora, más brevemente TEDH o Tribunal de Estrasburgo) en relación a un determinado aspecto del derecho a la tutela judicial efectiva, como es el derecho a ser informado de la acusación.

El valor concreto de las sentencias de este órgano jurisdiccional es conocido y pacifico, y descansa en la consideración de la propia e inevitable concisión de la formulación escrita del Convenio. Además de ello, la deseada ambigüedad en la regulación de las materias concretas ${ }^{24}$ hace imprescindible el desarrollo de una efectiva actividad de interpretación del material normativo convencional.

De esta tarea se hace cargo el mismo Tribunal de Estrasburgo, y eso es por dos razones distintas pero relacionadas:

23 Por ello, el TEDH llega a considerar justificado no revelar a la defensa la identidad de determinados testigos, ya que la protección contra represalias puede justificar suficientemente el mantenimiento del anonimato. Véase a tal propósito nuevamente el caso Doorson contra Países Bajos.

24 C. Morviducci, La protezione della libertá religiosa nel sistema del Consiglio d'Europa, en La tutela della libertà di religione, a cura di S. Ferrari e T. Scovazzi, Padova, 1988, p 42. 
- En primer lugar, porque es el mismo Convenio el que establece, en su art. $32^{25}$, que la interpretación de sus propias normas, así como la resolución de todas las cuestiones relacionadas con esta función hermenéutica, compete al TEDH.

- En segundo, sencillamente, porque no es separable el proceso de aplicación de la norma del de su interpretación, siendo este último, necesariamente previo al primero. Así, el Tribunal de Estrasburgo, para resolver todos aquellos casos de violación de derechos fundamentales que se le planteen, no tiene más remedio que interpretar el complejo de normas que está llamado a aplicar.

La actividad de interpretación del derecho, de esta manera, consiste esencialmente, en escoger entre un abanico de posibles significados, uno en concreto, llenando de sentido algo que de otras formas, no sería sino un "vacío significante". En ello, efectivamente, consiste el verdadero poder de los jueces, en esta discrecionalidad interpretativa, que encuentra dos límites concretos: por un lado, el texto objeto de la interpretación, que puede estar expuesto a manipulaciones de diferentes alcances, en función del rigor con el que se ha tratado su formulación; por otro el deber de los jueces —al que corresponde una concreta situación jurídico-subjetiva, reconocida tanto en el art. 6 del CEDH como, expresamente, en el art. $24 \mathrm{CE}$ - de motivar sus resoluciones.

De ello nos planteamos hablar, de cómo ha influido la jurisprudencia del TEDH en la jurisprudencia del Tribunal Constitucional Español, en relación al derecho a ser informado de la acusación.

\section{EL DERECHO A SER INFORMADO DE LA ACUSACIÓN EN LA JURISPRUDENCIA DEL TEDH}

\section{III.1. INTRODUCCIÓN}

El art. 6.3 letra c) del Convenio establece que "Todo acusado tiene, como minimo, los siguientes derechos [...] a ser informado, en el más breve plazo, en una lengua que comprenda y detalladamente, de la naturaleza y de la causa de la acusación formulada contra él”.

Se trata de una formulación que recoge un principio básico para el concreto desarrollo del "proceso equitativo" en el respeto de los postulados de igualdad y contradicción procesal que vienen exigidos por el primer

25 Art. 32 del CEDH: «La competencia del Tribunal se extiende a todas las cuestiones relativas a la interpretación y la aplicación del Convenio y de sus Protocolos que le sean sometidas en las condiciones previstas por los Arts. 33, 34 y 47. En caso de impugnación de la competencia del Tribunal, éste decidirá sobre la misma". 
apartado del art. 6 CEDH, es decir, el derecho a ser informado de la acusación $^{26}$.

Con ello, el Convenio pretende imponer a los Estados la obligación de proporcionar al acusado de un delito todo el conocimiento necesario - elementos jurídicos o fácticos - acerca de la acusación, para permitir el concreto y eficaz desarrollo del derecho a la defensa.

Para entender cuál es la ratio de este principio no podemos perder de vista la finalidad del proceso penal. El fin del procedimiento penal no consiste ni se resuelve exclusivamente en el intento de atribuir la comisión de hechos delictivos a un sujeto genérico, pues la misión del juicio es otra, distinta y mucho más compleja: encontrar e identificar el verdadero autor del crimen investigado. Además, para llevar a cabo esta tarea es necesario comprender exactamente cómo se desarrollan los hechos incriminados.

No pudiendo disponerse de instrumentos útiles para viajar en el tiempo y por ello capaces de llevar al Juez al sitio y al momento en los que se cometieron los hechos delictivos, la única alternativa posible de llevar a cabo esta reconstrucción está representada por el proceso penal y por una determinada forma de celebrarlo: el contradictorio.

Este principio pretende que las partes compartan y se comuniquen recíprocamente el contenido de las informaciones de las que disponen acerca de los elementos jurídicos y fácticos decisivos para la definición del proceso.

Es fácil comprender cómo, sin una adecuada información preprocesal y endoprocesal ${ }^{27}$, es materialmente imposible la realización de todas aquellas exigencias relativas al principio de contradicción e igualdad de oportunidades que el Convenio pretende.

A través de estas simples consideraciones es posible entender el alcance de las relaciones existentes entre los postulados recogidos en el primer párrafo del art. 6 del CEDH y los principios consagrados en los demás párrafos - particularmente el principio de información sobre la acusación-, pero no sólo esto, ya que también hay que tomar en consideración además, una estrecha red de conexiones entre los postulados del primer párrafo y los de los siguientes párrafos.

Es demostración de ello, por ejemplo, el importante vinculo lógico-jurídico existente ente el derecho a una información detallada sobre la acusación y el principio contenido en la letra b) del tercer párrafo del art. 6 que impone

26 Véase por ejemplo el caso Urterpentiger contra Austria, Sentencia de 24 de noviembre de 1986; o el caso Atner contra Austria de 22 de agosto de 1992; o el caso Foucher contra Francia de 18 de marzo de 1997.

27 J. MonTERo Aroca propone la distinción entre información preprocesal, que tendría lugar en el momento en que se realiza la detención preventiva, e información procesal, que tendría sin embargo lugar desde la incoación del proceso. (Derecho Jurisdiccional. Proceso Penal, Parte General, cit.). Nosotros proponemos una pequeña variación, refiriéndonos a la fase de instrucción del proceso penal como a la verdadera fase preprocesal, prescindiendo en nuestra clasificación de la detención preventiva. 
que el acusado disponga del "tiempo y las facilidades necesarias para la preparación de su defensa".

En este sentido no debemos considerar el primero de estos postulados como el presupuesto lógico del segundo, ya que se debe interpretar el concepto de "facilidades" como aquel conjunto indispensable de informaciones necesarias para la organización de la defensa ${ }^{28}$.

Otra importante relación es la que existe entre el Derecho a ser informado de la acusación y el principio contenido en el n. ${ }^{\circ} 2$ de del art. 5 del Convenio que reconoce la posibilidad para "cualquier persona detenida [de] ser informada en el más breve plazo de las razones de su prisión y de cualquier acusación formulada contra ella".

Vemos entonces que la información reviste una importancia básica también en relación a la detención preventiva, aunque es cierto que el contenido de la misma no es absolutamente igual al que exige el art. 6.3 letra a) del Convenio. De hecho el art. 5 n. ${ }^{\circ} 2$ obliga a la autoridad jurisdiccional a comunicar exclusivamente los supuestos de la detención o de la privación de libertad del sospechoso, mientras que la obligación referida al derecho a ser informado de la acusación es mucho más amplia.

Para ello analizaremos los aspectos más importantes referidos a estos postulados, preguntándonos, en particular, quién debe informar, cuál debe ser el contenido de esta información y cuál deba ser el tiempo de la misma. De esta forma, articularemos nuestra exposición en cuatro puntos básicos, es decir:

— sujetos activos y pasivos;

- objeto de la información;

- formas o modalidades de la información;

- tiempos de la información.

En nuestra exposición recurriremos, evidentemente, a una amplia jurisprudencia del Tribunal de Estrasburgo ${ }^{29}$.

\section{III.2. LOS SUJETOS DE LA INFORMACIÓN}

El concepto mismo de información evoca la idea de por lo menos dos individuos que se comunican entre ellos. Nada excluye sin embargo que sea

28 Somos conscientes, de todas formas, que la interpretación de esta expresión no se resuelve sólo con esta definición, sino que tiene un alcance mucho más amplio e importante.

29 Entre otros recordamos como los más relevantes para el derecho a ser informado de la acusación, los casos Albert y Le Compte contra Bélgica, Sentencia de 10 de febrero de 1983; Broziceck contra Italia, Sentencia de 19 de diciembre de 1989; Gea Catalán contra España, Sentencia de 10 de febrero de 1995; Kamasinski contra Austria, Sentencia de 19 de diciembre de 1989; Kyprianou contra Chipre, Sentencia de 27 de enero de 2004; Matoccia contra Italia, Sentencia de 25 de julio de 2000; Öcalan contra Turquía, Sentencia de 12 de marzo de 2003; Pelissier y Sassi contra Francia, Sentencia de 25 de marzo de 1999; Sadak contra Turquia, Sentencia de 17 de julio de 2001; Twalib contra Grecia, Sentencia de 9 de junio de 1998. 
sólo uno de los dos el sujeto llamado a trasmitir contenidos, o sobre el que incumba tal obligación: llamaremos a aquel individuo "sujeto activo de la información".

Evidentemente existirá, frente a él, alguien, destinatario de esta información, que definiremos "sujeto pasivo", o más claramente, titular del derecho a la información.

Volviendo al ámbito del proceso penal, estas consideraciones previas nos sirven para indicar, por un lado, cómo el derecho previsto por el art. 6.3 letra a) representa una garantía para todos los sujetos pasivos, tanto de la comunicación, como del proceso — en otras palabras, el acusado—; y por otro, como el suministro de esta información corre a cargo de la autoridad a la que corresponde la instrucción del proceso - el sujeto activo de nuestro postulado-.

Desafortunadamente, la realidad es un poco más compleja de lo que pueda parecer por el contenido de estas líneas, ya que, sobre todo la figura de "Sujeto pasivo" no es de fácil determinación a la hora de interpretar de manera concreta el concepto de "acusado", en relación al derecho a ser informado de la acusación.

Resumiendo, se trata de establecer quién es el titular del derecho en cuestión, partiendo de la definición ya dada, existiendo, por lo menos, dos teorías distintas acerca de este asunto tema.

Según una visión formal se puede considerar "acusado" - y por ello, repetimos, titular del Derecho a ser informado de la acusación- al sospechoso que pasa a adquirir este nuevo status mediante una declaración formal y expresa del Juez o de la autoridad competente. Resulta claro que se trata de una concepción limitativa del concepto objeto de análisis, y por ello descartada en la actualidad por el Tribunal de Estrasburgo ${ }^{30}$.

Otra construcción dogmática del concepto de "acusado", más amplia y por esto preferible, es la que considera como tal a todo sujeto acusado de una infracción.

Esta es, desde luego, la opinión compartida por el Tribunal de Estrasburgo cuando, considera que "para algunos, en el contexto de la Convención, las palabras 'acusado' y 'acusación penal' corresponden a una noción autónoma y deben ser interpretados por referencia a una situación material y no formal. En este sentido, este Tribunal estima que constituye acusación no solamente la notificación oficial del reproche de haber cometido una infracción, sino también cualquier medida que comporte repercusiones importantes sobre la situación del sospechoso "31.

Es ciertamente oportuno dedicar algunas palabras también al que hemos definido como el "sujeto activo de la información", o sea el destinatario de la obligación de informar: es decir, la autoridad judicial.

30 En realidad era la teoría adoptada por el TEDH al menos hasta el caso Imbricioscia contra Suiza, Sentencia de 24 noviembre de 1993, que marcó el cambio hacia la concepción material del concepto de acusado.

31 Caso Eckle contra Alemania, Sentencia de 15 de julio de 1982. 
El TEDH, a este propósito, se ha limitado a dejar suficientemente claro que la actitud del órgano encargado de comunicar la acusación debe desarrollar esta función con la máxima cautela - la expresión exacta utilizada en dos ocasiones ${ }^{32}$ es "extremadamente cauteloso»- En este sentido, creemos entender que el Tribunal de Estrasburgo pretende enfocar su atención no sólo sobre el contenido de la información, que deberá ser clara, exhaustiva y completa, sino, extensivamente, también sobre otros aspectos de igual importancia como son los modos de llevar a cabo esta comunicación: nos referimos, en primis, a la exigencia de comunicar todo lo necesario en el más breve plazo y, en secundis, a las formas de la comunicación, con el fin de no determinar la violación de otros derechos fundamentales como, por ejemplo, el derecho al honor.

\section{III.3. EL OBJETO DE LA INFORMACIÓN}

Hasta ahora hemos dejado suficientemente claro a quién compete dar la información y quién es el titular del derecho a recibirla. Pero lo cierto es que no hemos dicho mucho en relación al contenido de esta información.

El contenido está constituido fundamentalmente por dos categorías distintas — aunque íntimamente relacionadas-de elementos:

- en primer lugar, todos aquellos hechos constitutivos del ilícito penal que se atribuyen al acusado y sobre los que se va a desarrollar el debate en el proceso contradictorio;

- y, en segundo lugar, aspectos referidos a la calificación jurídica de estos hechos, a la determinación de las circunstancias concurrentes y a la pena correspondiente por la participación.

Hablamos, por lo tanto, no sólo de elementos puramente fácticos relativos al delito —-sobre todo referidos a la participación y por ello a la responsabilidad del acusado- sino también de elementos jurídicos o, por utilizar una expresión más propia, relacionados con la calificación jurídica de los hechos imputados, ya que ésta, como bien ha puesto en evidencia el TEDH, constituye parte imprescindible de la información sobre la acusación ${ }^{33}$.

Lo cierto es que este contenido particular de la información - la calificación jurídica de los hechos- puede cambiar en todo o en parte, especialmente en las fases preliminares del juicio, cuando la reconstrucción de lo que ha ocurrido y de cómo se ha verificado aún está en un estado inicial, aunque nada excluye que pueda ocurrir también después, al menos hasta el cierre del proceso.

32 Nos referimos a los casos Kamasinski contra Austria, Sentencia de 19 de diciembre de 1989, y Pelissier y Sassi contra Francia, Sentencia de 25 de marzo de 1999.

33 Nuevamente, Pelissier y Sassi contra Francia, Sentencia de 25 de marzo de 1999. 
Estas modificaciones han de ser comunicadas al acusado para que éste pueda articular eficazmente su defensa.

Un caso paradigmático en tema de variaciones en relación a la calificación jurídica de los hechos imputables es, sin duda, el ya citado Pelissier y Sassi contra Francia, en el que se detecta una violación del derecho contenido en el art. 6.3 letra a) en relación a la falta de comunicación de este tipo de información básica.

Se trata de un asunto en el que los demandantes resultan acusados por la autoría de un delito de quiebra, delito respecto del que articulan su propia defensa. Después son condenados como cómplices en el mismo por el Tribunal de Apelación.

En este caso, el TEDH, una vez detectada la manifiesta variación de la calificación jurídica de los hechos —desde "autores" a "cómplices»—, comprobó dos aspectos decisivos para la condena de Francia: por un lado resultó que los debates del proceso se habían referido exclusivamente a la supuesta autoría del delito, sin que se hablara nunca de la posible complicidad de los demandantes; por otro, parecía suficientemente cierto que la complicidad no había constituido elemento intrínseco de la acusación inicial, excluyéndose así a priori que los interesados pudieran saber de ella desde el principio del juicio.

Por ello el Tribunal de Estrasburgo estimó que el Tribunal de Apelación, en aplicación del art. 6.3 letra a) del Convenio, debía de haber comunicado aquella variación de la calificación jurídica, de forma concreta y en tiempo útil, permitiendo de esta manera el efectivo ejercicio del derecho de defensa por parte de los demandantes.

\section{III.4. LAS MODALIDADES DE LA INFORMACIÓN}

Por lo que atañe a la forma en la que se debe dar la información necesaria para la articulación de la defensa, el art. 6.3 letra a) del Convenio establece dos criterios concretos, exigiendo que tal comunicación sea detallada y en una lengua comprensible para su destinatario.

Empezando con este último presupuesto, la familiaridad del acusado con el idioma empleado para comunicarle la acusación se trata de una condición lógica y necesaria para una efectiva realización de la finalidad perseguida por el derecho a ser informado de la acusación.

Es, por lo tanto, evidente que todas las funciones que se atribuyen a este derecho quedarían anuladas y frustradas en aquellas hipótesis en las que el destinatario no pudiera comprender la acusación, por haber sido comunicada en una lengua desconocida para él.

En relación a esta exigencia del art. 6.3 letra a) $\mathrm{CEDH}$, hay que recordar el caso Kamasinski contra Austria.

En este supuesto, el demandante denunció que la información acerca de la acusación no se había hecho por escrito y, además, en una lengua que él no comprendía: el inglés. El Tribunal de Estrasburgo estableció que, aunque el 
Convenio no explicite que la información sea traducida y entregada por escrito al acusado extranjero, sí deja suficientemente claro que es imprescindible poner un particular cuidado en notificar la acusación al interesado, ya que esta tarea representa, sin lugar a dudas, un momento determinante en las investigaciones penales.

Por esta razón, se estima la falta de traducción como importante desventaja para el acusado, que, no pudiendo conocer los presupuestos facticos y jurídicos de su incriminación, no se encuentra con las condiciones necesarias para su propia defensa.

A pesar de todo eso, en concreto, el TEDH reputó que el acto de acusación era relativamente sencillo y que, además, habiéndose procedido al interrogatorio del acusado durante un tiempo suficientemente largo, podía legítimamente considerarse que no quedaban dudas para él sobre el objeto de la acusación y sobre los hechos imputados. Atendiendo a estas razones, concretas y compartibles, el Tribunal de Estrasburgo desestimó el recurso.

Nos parece interesante concluir este tema relacionado con la comprensión de la información, con una consideración que, aunque banal, es rica en efectos prácticos y jurídicos. No hay que olvidar la posibilidad para el Estado de demostrar que el sujeto destinatario de la información, aunque extranjero, es capaz de entender el idioma utilizado para redactar el acto de acusación, ya que en este caso, el Estado quedaría excluido de ser condenado por violación del art. 6.3 letra a) del Convenio, al menos en lo relativo a la condición de comprensión de la lengua.

Por lo que atañe, sin embargo, a la forma detallada de la información, el TEDH ha dejado claro que no se impone ninguna formalidad concreta a los Estados contratantes, para que pueda considerarse cumplido este presupuesto.

Se puede considerar que los únicos requisitos exigidos son la forma clara de la acusación para hacerla comprensible a cualquiera y, sobre todo, el hecho de que no sea demasiado genérica, en relación a los contenidos facti$\cos$ y jurídicos ${ }^{34}$, por las razones ya señaladas y que están relacionadas con las exigencias defensivas.

\section{III.5. LOS TIEMPOS DE LA INFORMACIÓN}

El último aspecto que nos corresponde analizar respecto al derecho a ser informado de la acusación es el relativo al momento en el que esta información tiene que ser comunicada, tema sobre el cual, el art. 6.3 letra a), no dice otra cosa sino que la información debe ser comunicada "en el más breve plazo".

En primer lugar queremos poner en evidencia la estrecha correlación existente entre este elemento y el problema relativo al significado que hay que dar a la expresión "sujeto pasivo de la información" pues, como hemos

34 Véase el caso Sadak contra Turquía, Sentencia de 17 de julio de 2001, y una vez más Pelissier y Sassi contra Francia y Kamasinski contra Austria. 
visto, este concepto, excesivamente genérico, también exige una determinación concreta de su alcance que sólo puede darse observando el momento exacto en el que un individuo pasa de estar libre de cualquier imputación a ser acusado de un delito y, por lo tanto, destinatario de la necesaria información sobre el contenido de su acusación.

A pesar de esta "estrecha relación" no podemos pensar que exista una absoluta sincronía entre la adquisición del status de acusado y el momento en que debe realizarse la obligación de informar a este sujeto, pues, por un lado, el Convenio no adopta una postura tan clara y, por otro, no podemos que olvidar todo el complejo de exigencias relacionadas con el secreto del sumario que pueden exigir, para una correcta y eficaz instrucción del caso, retrasar en el tiempo el momento de la comunicación de la acusación.

Por ello se justifica el hecho de que el Convenio haya adoptado una formulación bastante genérica al indicar simplemente que la información tenga que ser comunicada "en el más breve plazo".

Evidentemente ha sido tarea del Tribunal de Estrasburgo ofrecer claves de interpretación más concretas de esta amplia y etérea expresión, poniendo la atención sobre todo en la necesidad de realizar la comunicación sobre la acusación en tiempo útil y oportuno, esto es, en un momento procesal que permita al imputado conocer los elementos de la acusación a fin de poder articular sus alegaciones de defensa ante el Tribunal ${ }^{35}$.

A este respecto nos parece interesante citar el caso Kyprianou contra Chipre $^{36}$ relativo a un episodio en el que un Tribunal nacional, una vez suspendido el proceso a quo por haber utilizado el abogado de una de las partes expresiones injuriosas, lo reanudó notificando al mismo la imposición de una pena de cinco días de prisión por desacato, sin realizar ninguna comunicación previa del cargo al interesado. En este asunto, el TEDH consideró que se había violado el art. 6.3 letra a) del $\mathrm{CEDH}$ por no haberse realizado ninguna notificación previa en tiempo útil de la acusación contra el letrado, de manera que éste sólo tuvo conocimiento de la misma cuando se le notificó la resolución condenatoria.

\section{EL DERECHO A SER INFORMADO DE LA ACUSACIÓN EN LA JURISPRUDENCIA DEL TC}

\section{IV.1. INTRODUCCIÓN}

A la hora de acercarnos al análisis de la jurisprudencia del TC sobre el derecho a ser informado de la acusación, estimamos oportuna una conside-

35 Véase en particular los casos Sadak contra Turquia, Sentencia de 17 de julio de 2001 y Matoccia contra Italia, Sentencia de 25 de julio de 2000.

36 Caso Kyprianou contra Chipre, Sentencia de 27 de enero de 2004. 
ración preliminar: nos enfrentamos a una garantía que se caracteriza por una doble vertiente:

- por un lado, representa un instrumento predominantemente procesal (quizás más oportuno sería decir "preprocesal", a continuación analizaremos por qué),

- por otro, es un derecho constitucional, siendo recogido por los arts. 17.3 y 24.2 de la $\mathrm{CE}^{37}$.

Como ya hemos apreciado analizando la jurisprudencia del Tribunal Europeo de Derechos Humanos, el derecho a ser informado de la acusación no puede ser entendido de manera aislada, ya que forma parte, indiscutiblemente, del contenido esencial del principio de contradicción y, del mismo modo, constituye un presupuesto necesario y fundamental del derecho de defensa, puesto que el imputado o acusado muy difícilmente puede participar de forma activa - ejerciendo su derecho a defenderse- en un proceso en el que desconoce todo o parte de lo que se le imputa o acusa.

En este sentido, podemos afirmar que el derecho a ser informado de la acusación representa un derecho público sujetivo, de naturaleza fundamental y carácter procesal, por el que el titular, imputado o acusado, en un proceso penal, debe recibir de los órganos públicos encargados de la persecución penal, desde los momentos iniciales del proceso, y hasta su conclusión, toda la información acerca del hecho punible que se le imputa o del que se le acusa, así como de los demás derechos constitucionales y ordinarios reconocidos al imputado o acusado.

Es cierto que el derecho a ser informado de la acusación no puede ser interpretado aisladamente, en particular, sin ponerlo en relación con otro derecho fundamental incluido en el mismo art. 24: el derecho a la defensa ${ }^{38}$. Así lo pone en evidencia el mismo Tribunal Constitucional en la STC 181/1998, de 17 de septiembre, en la que se señala que "en virtud de las exigencias del principio acusatorio nadie puede ser condenado si no se ha formulado contra él una acusación de la que haya tenido oportunidad de defenderse, pues ello es necesario para poder ejercer el derecho de defensa en el proceso penal, ${ }^{39}$.

37 Art. 17.3 CE: "Toda persona detenida debe ser informada de forma inmediata, y de modo que le sea comprensible, de sus derechos y de las razones de su detención, no pudiendo ser obligada a declarar. Se garantiza la asistencia de abogado al detenido en las diligencias policiales y judiciales, en los términos que la ley establezca".

Art. 24.2 CE: "Asimismo, todos tienen derecho al Juez ordinario predeterminado por la ley, a la defensa y a la asistencia de letrado, a ser informados de la acusación formulada contra ellos, a un proceso público sin dilaciones indebidas y con todas las garantías, a utilizar los medios de prueba pertinentes para su defensa, a no declarar contra si mismos, a no confesarse culpables y a la presunción de inocencia...".

38 F. Cordón Moreno, Las garantias constitucionales del proceso penal, Editorial Aranzadi, Pamplona, 1999, p. 145.

39 Igualmente recordamos las SsTC 141/1986, de 12 de noviembre, y 11/1992, de 27 de enero. 
Como es sabido, el principio acusatorio conlleva tres exigencias ${ }^{40}$ :

- que no haya ni juicio ni condena sin previa acusación;

- que quien acuse no juzgue también;

- que quien juzga haga referencia sólo al objeto de la acusación.

Vemos cómo, sobre todo, la primera parte de este principio se ve íntimamente relacionada con el derecho objeto de nuestro estudio, puesto que este dogma se vería violado en el caso de que se condenara a alguien sin previa información acerca de su acusación. No podemos decir lo mismo en relación con la segunda parte del principio acusatorio, puesto que la coincidencia en la misma persona de la figura del acusador y del juzgador no se ve incompatible con el derecho a ser informado de la acusación ${ }^{41}$.

El tercer punto que constituye el principio acusatorio, sin embargo, sí podemos, nuevamente, ponerlo en relación con la garantía procesal de la que nos ocupamos. Así vemos como el Tribunal Constitucional ${ }^{42}$ en su sentencia 181/1998 pone en evidencia que "el reconocimiento que el artículo 24 de la Constitución realiza de los derechos a la tutela judicial efectiva sin indefensión, a ser informado de la acusación y a un proceso con todas las garantías supone, conjuntamente considerados, que en todo proceso penal el acusado ba de conocer la acusación contra él formulada para poder defenderse de manera contradictoria frente a ella, y que el pronunciamiento del Juez o Tribunal ha de efectuarse precisamente sobre los términos del debate, tal y como ban sido formulados en las pretensiones de la acusación y defensa; lo cual significa, entre otras cosas que ha de existir siempre una correlación entre la acusación y el fallo de la sentencia "43.

También cabe recordar que la inclusión del derecho a ser informado de la acusación dentro del principio acusatorio no es pacífica en toda la doctrina. Así se considera que la garantía constitucional proporcionada por este principio debe ubicarse, según sus distintas manifestaciones, o en el derecho al juez imparcial, o más bien en el derecho a no padecer indefensión, pero ciertamente no en el derecho ser informado de la acusación ${ }^{44}$. Sin embargo, como hemos visto, consideramos que, por lo menos, una de las tres diferen-

40 Entre otros recordamos, T. Armenta Deu, Principio acusatorio y Derecho Penal, Ed. Bosch, Barcelona, 1995.

41 De hecho, la experiencia procesal española contempla el caso del procedimiento sancionador administrativo, donde no rige el principio acusatorio, pero igualmente se respeta el derecho fundamental del que hablamos.

42 STC 225/1997, de 15 de diciembre.

43 En este mismo sentido, recordamos también las SsTC 54/1985, de 18 de abril; 84/1985, de 08 de julio; 104/1985, de 04 de octubre; 41/1986, de 02 de abril; 136/1986, de 03 de noviembre; 168/1990, de 05 de noviembre; 47/1991, de 28 de febrero; 182/1991, de 30 de septiembre; 36/1996, de 11 de noviembre; 230/1997, de 16 de febrero.

44 F. CAAmaño DomínguEZ, "Algunas consideraciones sobre el derecho a ser informado de la acusación en la jurisprudencia del Tribunal Constitucional", en La Constitución y la práctica del Derecho, Ed. Aranzadi y BCH, p. 467. 
tes partes a través de las cuales se desarrolla el principio acusatorio, la que se refiere a la necesidad de una acusación previa a cualquier condena - y también a la información sobre esta acusación-, tiene perfecta cabida en este derecho objeto de nuestro estudio.

\section{IV.2. LA DENOMINACIÓN LEGAL DEL DERECHO}

Estimamos oportuno, ahora, detenernos, brevemente, sobre la denominación legal de este derecho, puesto que la expresa referencia que en él se hace al estatus de "acusado" puede inducir a error acerca de la titularidad de este derecho y de los momentos en los que, por un lado, hay que informar y, por otro, ser informado.

En este sentido, podemos considerar que no es del todo correcta la expresión "derecho a ser informado de la acusación", pues, si quisiéramos interpretarla en un sentido estricto, tendríamos que referirla únicamente al sujeto "acusado", excluyendo la posibilidad de extender esta garantía a ese otro sujeto que aun no es parte de un proceso ya instaurado y en contra del cual el Ministerio Fiscal, no ha aun formulado su acusación: el imputado, es decir una persona respecto a la que se formula una imputación, es decir la atribución de un delito por parte de la acusación.

La diferencia es, ictu oculi, sustancial.

Mientras la acusación se refiere a una fase madura y avanzada del procedimiento, la imputación, necesariamente, hace retroceder nuestra atención a una fase precedente -incluso preprocesal, como hemos dicho- en la que, según cuanto afirma García Rada: "...se atribuye a una persona la comisión de un hecho que la ley penal califica de delito. La imputación está contenida en la denuncia que presenta el Ministerio Público. La imputación debe reunir dos requisitos: debe ser concreta y debe ser integra. Lo primero significa que debe contener una denuncia cierta de un hecho que es delictuoso para la ley; deberá precisarlo en sus contornos, no siendo necesario detalles íntimos que se darán en la ratificación. Debe ser integra conteniendo todo aquello que constituye el delito denunciado, sin recortes ni limitaciones y señalando quiénes lo cometieron sin omitir alguno de los autores o cómplices...." ${ }^{45}$.

De esta manera vemos cómo el derecho a ser informado de la acusación nace en el mismo momento en el que existe una imputación, formal o material, contra alguien, incluso — es cierto - cuando se realice una detención policial o judicial — tal como esté prevista explícitamente por el art. 17.3 $\mathrm{CE}$ - o cuando se recurra a otra medida cautelar, como la prisión provisional, o cuando se admita la denuncia o querella o se dicte un auto de procedimiento.

45 D. García Rada, Manual de Derecho Procesal Penal, séptima edición, Lima (Perú) 1982, p. 104 . 
Igualmente, es preciso poner en evidencia que este derecho no puede entenderse referido como exclusivamente a la fase inicial del proceso sino que se exige una continua notificación de todo lo que puede afectar a la calificación jurídica del delito, objeto del proceso, a lo largo de todo el juicio.

En este sentido, las posibles modificaciones debidas a la realización de los actos de investigación, o, después del juicio oral, a los resultados probatorios obtenidos deberán ser comunicadas, pues, la posibilidad de conocer estos nuevos elementos permitirán garantizar el derecho de defensa y dar mejor cumplimiento al principio de contradicción de las partes.

Por lo que se refiere, sin embargo, al contenido esencial, es oportuno, en este caso también, hacer referencia a tres elementos distintos:

- subjetivo;

- objetivo;

- temporal.

Por esto, en nuestro análisis, nos detendremos en primer lugar, sobre los sujetos obligados a proporcionar esta información - fundamentalmente las autoridades públicas encargadas de la persecución penal- y, posteriormente, sobre el sujeto al que se le debe proporcionar esta información: es decir, el imputado o el acusado — según el momento procesal en el que nos encontramos-.

Desde el punto de vista objetivo, ya sabemos que la información tiene que contener el hecho criminal imputado y objeto del proceso, pero es posible entender este derecho como referido también a todos aquellos derechos de carácter procesal que corresponden al sujeto pasivo en razón de su condición: concretamente, el derecho de autodefensa, el derecho de defensa técnica, el derecho a no declarar contra sí mismo, el derecho a no confesarse culpable y el derecho a ser asistido por un interprete.

Pasamos, entonces, al análisis concreto de los aspectos esenciales de este derecho a la luz de la jurisprudencia de nuestro Tribunal Constitucional.

\section{IV.3. LOS SUJETOS DE LA INFORMACIÓN}

Ya hemos definido este derecho, objeto de nuestro estudio, como un derecho público sujetivo ${ }^{46} \mathrm{y}$, sobre todo, como un derecho fundamental procesal que obliga directamente todos los poderes públicos ${ }^{47}$.

Además, esta garantía se encuentra íntimamente relacionada con otros principios fundamentales que integran el más amplio derecho a la tutela ju-

46 En este sentido recordamos entre otras las SsTC 141/1986, de 12 de noviembre; 2/1994, de 17 de mayo. abril.

47 Esto es lo que ha establecido el mismo TC desde el principio en la STC 8/1981, de 8 de 
dicial efectiva, en particular el principio de contradicción y el derecho de defensa $^{48}$. En este sentido, el Tribunal Constitucional, en la STC 297/1993, de 18 de octubre, recuerda que ninguna defensa puede ser eficaz si el imputado no conoce con anterioridad los hechos en que se fundamenta la acusación, a fin de oponer frente a ellos las oportunas excepciones y defensas "

Desde un punto de vista lógico estimamos oportuno empezar este análisis con la descripción de todos aquellos sujetos sobre los que incumbe la obligación ${ }^{50}$ de informar acerca de la acusación o imputación. Así, antes de empezar nuestro examen del perfil subjetivo de esta garantía procesal, queremos recordar que el primer contenido esencial de este derecho es que una autoridad pública está obligada a informar de la acusación. Con esta expresión "autoridad pública", nos referimos tanto al juez, como al Ministerio Fiscal e incluso a la policía judicial.

\section{IV.3.a) El Juez}

Sin alguna duda compete a la autoridad judicial llevar a cabo con mayor intensidad esta labor de información.

En este sentido, según establece el art. 303 de la Ley de Enjuiciamiento Criminal (en adelante LECRIM) al Juez de instrucción compete «hacer constar la perpetración de los delitos con todas las circunstancias que puedan influir en su calificación...".

En esta labor de información, que se le exige a la autoridad judicial, juega un papel fundamental el "auto de procesamiento" a través del cual, en todos los procesos ordinarios por delitos graves ${ }^{51}$ cuando del sumario resulte algún indicio de culpabilidad contra un sujeto determinado este último conoce la existencia de un proceso en su contra.

48 V. Fiaren GuIllén, La disponibilidad del derecho de defensa en el sistema acusatorio español, en "Temas del Ordenamiento Procesal", tomo II, Ed. Tecnos, Madrid, 1987, p. 1245; J. MoNtero, en Montero, Ortells, Gómez Colomer, Montón, Derecho Jurisdiccional I. Parte General, Ed. Tirant Lo Blanch, 6. ${ }^{a}$ ed., Valencia 1997, p. 327; V. Gimeno SENDRA, El derecho de defensa, en "Constitución y Proceso", Ed. Tecnos, Madrid, 1988, p. 100; J. L. Gómez Colomer, El Proceso penal español para no juristas, Ed. Tirant Lo Blanch, 2. ${ }^{a}$ Ed. Valencia, 1997, p. 77; G. BetTIOL, Instituciones de derecho penal y procesal, Ed. Bosch, Barcelona, 1977, (Traducción de GuTiÉRREZ-Alviz y F. ConRadi), pp. 255 y 256; A. Del Moral García, El Derecho a ser informado de la acusación en el procedimiento abreviado para determinados delitos, en "Actualidad Penal", n. ${ }^{\circ}$ 13, 1989, p. 650.

49 En este mismo cauce, SsTC 9/1982, de 10 de marzo, 44/1983, de 24 de mayo, 141/1986 de 12 de noviembre, 30/1989 de 7 de febrero, 170/1990 de 5 de noviembre, 47/1991 de 28 de febrero, 62/1994 de 28 de febrero, 277/1994 de 17 de octubre, 36/1996 de 11 de marzo, 129/1996 de 9 de julio.

50 El mismo TC pone en evidencia el carácter obligatorio de esta información por parte de los poderes públicos en las STC 2/1994 de 17 de enero, 141/1986 de 12 de noviembre, 2/1994 de 17 de mayo.

51 Este auto ha desaparecido para los procesos abreviados, juicios de falta y para los procesos ante el Tribunal de Jurado. 
Así, vemos como este auto contiene fundamentalmente la ilustración de los hechos delictivos que se imputan al sujeto, por el que será posible, a partir del momento de su conocimiento organizar una estrategia defensiva, además de adquirir todo el complejo de situaciones jurídicas de garantía que constituyen el derecho a la tutela judicial efectiva: in primis el derecho de defensa ${ }^{52}$.

Es cierto también que, dentro del ordenamiento jurídico español, el auto de procesamiento no es la única manera para conocer la existencia de un proceso, puesto que existen formas más llamativas que, aunque indirectamente, alcanzan la misma finalidad.

La detención o la adopción de una medida cautelar son instrumentos procesales cuyo empleo obliga a la autoridad judicial a justificar su necesidad dando a conocer al interesado los hechos por cuya comisión se le considera sospechoso.

Por lo que se refiere al momento en el que se abre el juicio oral, vemos cómo la notificación, la citación o emplazamiento realizado por el secretario judicial, bajo las órdenes de la autoridad judicial, siguen representando actos en los que se consagra y concreta la información de la acusación ${ }^{53}$.

\section{IV.3.b) El Ministerio Fiscal}

Como es sabido, el Ministerio Fiscal actúa dentro del proceso haciéndose cargo, fundamentalmente, de la acusación pública. Sin embargo, en determinados casos su función se extiende a la instrucción del proceso mismo. En este sentido, la obligación de informar puede considerarse como consecuencia y efecto de la función instructora del proceso de la que el mismo Ministerio Fiscal, ocasionalmente, se hace cargo.

Así, cuando la acusación pública, interviniendo en el procedimiento preliminar o sumario, realiza esta función de instrucción, el Ministerio Fiscal se encuentra obligado a informar al imputado de cómo se está concretando la acusación contra él.

52 Art. 118 LECRIM: "Toda persona a quien se impute un acto punible podrá ejercitar el derecho de defensa, actuando en el procedimiento, cualquiera que éste sea, desde que se le comunique su existencia, haya sido objeto de detención o de cualquiera otra medida cautelar o se haya acordado su procesamiento, a cuyo efecto se le instruirá de este derecho. La admisión de denuncia o querella y cualquier actuación procesal de la que resulte la imputación de un delito contra persona o personas determinadas, será puesta inmediatamente en conocimiento de los presuntamente inculpados. Para ejercitar el derecho concedido en el párrafo primero, las personas interesadas deberán ser representadas por Procurador y defendidas por Letrado, designándoseles de oficio cuando no los hubiesen nombrado por sí mismos y lo solicitaren y, en todo caso, cuando no twvieran aptitud legal para verificarlo. Si no hubiesen designado Procurador o Letrado, se les requerirá para que lo verifiquen o se les nombrará de oficio si, requeridos, no los nombrasen, cuando la causa llegue a estado en que se necesite el consejo de aquellos o hayan de intentar algún recurso que biciese indispensable su actuación.

53 J. Montero, en Montero, Ortells, Gómez Colomer, Montón, Derecho Jurisdiccional..., op. cit., t. I, p. 404. 
Queda, pues, una pregunta importante por contestar: es decir, ¿cuándo el Ministerio Fiscal actúa desarrollando esta función de instrucción que determina la obligación de informar al imputado acerca de su condición procesal?

La intervención del fiscal como instructor se da en el procedimiento preliminar del proceso abreviado ${ }^{54}$, aunque debemos recordar que la instrucción llevada a cabo por el Juez es, tal como establece el art. 785bis.3 LECRIM, prioritaria y excluyente.

En este procedimiento particular, el Ministerio Fiscal se ve obligado a comunicar al sujeto citado para la comparecencia todo lo relacionado con la imputación, en particular, la descripción del hecho punible, acompañada por la calificación legal del mismo ${ }^{55}$.

\section{IV.3.c) La Policía Judicial}

Cabe preguntarse si la Policía Judicial puede considerarse como sujeto destinatario de la obligación de informar acerca de la acusación a la persona interesada. En primer lugar, hay que poner en evidencia que, como establece la Constitución en su art. 126, a la policía judicial competen propiamente las "funciones de averiguación del delito y descubrimiento $y$ aseguramiento del delincuente, en los términos que la ley establezca", funciones que se ven más detalladamente especificadas por el Título III de la Ley Criminal, en particular, por el art. 282 LECRIM, en el que se establece claramente que "será obligación de todos los que la componen, averiguar los delitos públicos que se cometieren en su territorio o demarcación; practicar, según sus atribuciones, las diligencias necesarias para comprobarlos y descubrir a los delincuentes, y recoger todos los efectos, instrumentos o pruebas del delito de cuya desaparición hubiere peligro, poniéndolos a disposición de la Autoridad Judicial".

Desde el punto de vista que más nos interesa, el relativo a la información, vemos cómo es tarea de la Policía Judicial comunicar a la Autoridad Ju-

54 Según lo que establece el art. 785 bis y 789.3 LECRIM. En realidad hay que señalar que, aunque la LO 7/1988 establecía un incremento de las funciones instructoras para el Ministerio Fiscal, la regulación final, a través de los arts. 781 y 785bis de la LECRIM, ha acabado por representar, como pone en evidencia la STS de 25 de junio de 1993 un ensayo para el caso en que se estableciera la instrucción por el Fiscal. V. Moreno Catena, en Gimeno, Moreno, Cortés, Derecho Procesal. Proceso Penal, ed. 1993, p. 774; M. Ortells Ramos, El nuevo procedimiento penal abreviado: aspectos fundamentales, Justicia 89, pp. 545-568; M. OrTELLs RAmos, Nuevos poderes para el Ministerio Fiscal en el proceso penal: limites constitucionales y valoración político-juridica, RDPc 1990, n. ${ }^{\circ}$ 2, pp. 223-258, J. L. Gómez Colomer, El Fiscal instructor, justicia 96, n. ${ }^{\circ}$ 2, p. 274 y ss.

55 Es cierto que esta calificación jurídica, por producirse en un momento preliminar del proceso, no impedirá sucesivas modificaciones. En este sentido M. OrTElls Ramos, en MORENO, ALmagro, Cortés, Gimeno, el nuevo proceso penal. Estudios sobre la Ley Orgánica 7/1988, Ed. Tirant lo Blanch, Valencia 1989, p. 73, y también J. L. Gómez Colomer, El Fiscal instructor, Justicia 96, n. ${ }^{\circ}$ 2, p. 274 y ss. 
dicial todo lo relacionado con la reconstrucción de los hechos delictivos. En este sentido, el art. 292 LECRIM $^{56}$ impone a los miembros de las fuerzas del orden la realización de un atestado en el que resulten especificados los hechos penalmente relevantes, las diligencias practicadas, las declaraciones e informaciones recolectadas y, en general, cualquier elemento que pueda servir a probar la existencia de un delito.

Igualmente, establece el art. 297 LECRIM $^{57}$ que estos atestados y declaraciones cobran el valor de denuncia, y, para que puedan servir como pruebas de cargo en el sucesivo juicio oral, se exige que el miembro de la Policía Judicial, que de ellos es autor, los reitere o ratifique como testigo.

Acerca de este último punto, es oportuno detenerse, aunque brevemente, en el análisis de dos Sentencias del Tribunal Supremo, la primera, la n. 450 de 23 de enero de 1987 y, la segunda, la n. 173 de 14 de octubre de 1997. En estos fallos de la suprema corte, vemos cómo se le puede reconocer, alternativamente, un triple valor a los atestados de la Policía Judicial en función del contenido de los mismos. Así, cuando contienen opiniones o informes no cualificados de la Policía Judicial o cuando recogen declaraciones de imputados o testigos, tienen el valor de simples denuncias.

Sin embargo, si hablamos de dictámenes o informes de los Gabinetes especializados y pertenecientes a la Policía Judicial, estos documentos adquieren la dignidad de informes periciales, sobre todo si son ratificados en presencia del juez durante el juicio oral.

$\mathrm{Si}$ los informes, en cambio, contienen diligencias objetivas y de resultado incuestionable, estos adquieren la dignidad de verdaderas pruebas, sin perjuicio de la prueba testifical ${ }^{58}$.

Según lo establecido por el art. 17.3 CE «toda persona detenida debe ser informada de forma inmediata, y de modo que le sea comprensible, de sus derechos y de las razones de su detención..... El caso más relevante en el que la Policía Judicial realiza una inmediata labor de información acerca de la acusación lo encontramos en el caso de la detención. Esto ocurre, tal como es-

56 Art. 292 LECRIM: "Los funcionarios de Policia judicial extenderán, bien en papel sellado, bien en papel común, un atestado de las diligencias que practiquen, en el cual especificarán con la mayor exactitud los hechos por ellos averiguados, insertando las declaraciones e informes recibidos y anotando todas las circunstancias que hubiesen observado y pudiesen ser prueba o indicio del delito. La Policía Judicial remitirá con el atestado un informe dando cuenta de las detenciones anteriores y de la existencia de requisitorias para su llamamiento y busca cuando asi conste en sus bases de datos".

57 Art. 297 LECRIM: "Los atestados que redactaren y las manifestaciones que hicieren los funcionarios de Policia judicial, a consecuencia de las averiguaciones que hubiesen practicado, se considerarán denuncias para los efectos legales. Las demás declaraciones que prestaren deberán ser firmadas, y tendrán el valor de declaraciones testificales en cuanto se refieran a hechos de conocimiento propio. En todo caso, los funcionarios de Policía judicial están obligados a observar estrictamente las formalidades legales en cuantas diligencias practiquen, y se abstendrán bajo su responsabilidad de usar medios de averiguación que la Ley no autorice".

58 Según J. L Gómez Colomer, El Proceso penal español..., op. cit., p. 183 y ss., en este último caso nos hallamos ante pruebas documentales o periciales. 
tablece el art. 520.2 LECRIM $^{59}$, cuando la Policía Judicial lleva a cabo una detención de un sujeto como consecuencia de la sospecha de que esta misma persona haya cometido o esté cometiendo un delito ${ }^{60}$.

\section{IV.3.d) El inculpado}

Analizados los sujetos destinatarios de la obligación de informar acerca de la acusación, debemos detenernos en el análisis de la figura del acusado.

En primer lugar, hay que señalar una dificultad de tipo definitorio puesto que, generalmente, se utilizan de manera indiscriminadas los términos "imputado" o "acusado" como sinónimos el uno del otro, aunque es cierto que, desde un punto de vista semántico, los significados de estas dos palabras no coinciden absolutamente.

En este sentido, vemos cómo por "imputado" se entiende aquel sujeto respecto al cuál ha sido formulada una imputación y contra el que se ejerce la acción pública. Sin embargo, con la expresión "acusado" se indica aquel sujeto frente al que se declara la apertura de la vista pública.

A la luz de estas consideraciones nos parece oportuno escoger una tercera vía para indicar el titular del derecho a obtener información acerca de la propia acusación, una tercera vía más genérica y, por lo tanto, menos precisa, pero capaz de ser, necesariamente, referible a una fase concreta del proceso: hablaremos entonces de inculpado ${ }^{61}$.

Sin embargo, y a pesar de la especial importancia que, en Derecho, cobra el significado de las palabras y el correcto uso de las mismas en función de su verdadero significado, tenemos que admitir que el problema planteado re-

59 Art. 520.2 LECRIM: "Toda persona detenida o presa será informada, de modo que le sea comprensible, y de forma inmediata, de los hechos que se le imputan y las razones motivadoras de su privación de libertad, asi como de los derechos que le asisten y especialmente de los siguientes: 1. Derecho a guardar silencio no declarando si no quiere, a no contestar alguna o algunas de las preguntas que le formulen, o a manifestar que sólo declarará ante el Juez. 2. Derecho a no declarar contra si mismo y a no confesarse culpable. 3. Derecho a designar Abogado y a solicitar su presencia para que asista a las diligencias policiales y judiciales de declaración e intervenga en todo reconocimiento de identidad de que sea objeto. Si el detenido o preso no designara Abogado, se procederá a la designación de oficio. 4. Derecho a que se ponga en conocimiento del familiar o persona que desee, el becho de la detención y el lugar de custodia en que se halle en cada momento. Los extranjeros tendrán derecho a que las circunstancias anteriores se comuniquen a la Oficina Consular de su país. 5. Derecho a ser asistido gratuitamente por un intérprete, cuando se; trate de extranjero que no comprenda o no bable el castellano. 6. Derecho a ser reconocido por el Médico forense o su sustituto legal y, en su defecto, por el de la Institución en que se encuentre, o por cualquier otro dependiente del Estado o de otras Administraciones Públicas".

60 Véase a este propósito la STS 30 de junio de 1997.

61 V. Fairén Guillén, El "encausado" en el proceso penal español, en "Temas del ordenamiento procesal", t. II, Ed. Tecnos, Madrid, 1987, p. 119; J. Montero, en Montero, Ortells, Gómez Colomer, Montón, Derecho Jurisdiccional..., op. cit., t. I, p. 75; M. Serra Domínguez, El imputado, en Estudios de Derecho Procesal, Ed. Ariel, Barcelona, 1969, p. 673 y ss.; T. MuÑOz RoJAs, El imputado en el proceso penal, Ed. Publicaciones del Estudio General de Navarra, Pamplona, 1958. 
presenta sólo un problema aparente, puesto que la adquisición del uno u otro estatus, de acusado o imputado, no cambia, en la sustancia, el hecho de ser destinatario de una serie de garantías procesales, que contribuyen a hacer del sujeto — de todas formas - inculpado ya no sólo un medio de prueba o un objeto de la investigación, sino una persona destinataria y titular de una compleja tutela constitucional, que, como ya sabemos, consiste, incluso, en recibir toda la información necesaria y oportuna para poder articular una defensa adecuada.

La existencia de garantías constitucionales consagradas tanto en el art. 24 CE como en el art. $6 \mathrm{CEDH}$, como, en particular, el derecho a no declararse culpable, pueden llevarnos a pensar en el "inculpado" como en un sujeto que, dentro de las dinámicas procesales, no está llamado a desarrollar participación activa alguna. Sin embargo, es más bien lo contrario.

En este sentido, si es cierto y pacifico que el proceso representa un mecanismo dirigido a la reconstrucción de la verdad procesal, y no a la determinación de "un culpable" — sea quien sea-, todas las contribuciones que puedan provenir del sujeto acusado/imputado serán necesarias y esenciales. No obstante esto, es preciso recordar que estas contribuciones y la auspiciada participación activa del inculpado no tienen por qué traducirse, necesariamente, en la asunción por parte de este sujeto de responsabilidades, ni tiene que frustrar un derecho fundamental ya citado: el derecho fundamental a no declararse culpable.

Vemos, entonces, cómo la posición procesal del acusado/imputado se caracteriza por un doble perfil. Siendo éste, ciertamente parte pasiva del proceso, sufre determinadas medidas que limitan derechos y libertades constitucionales, pero, por otro lado, es parte activa, ya que participa efectivamente en el proceso mismo.

Así, es cierto que, si en una fase preliminar del procedimiento penal es posible y natural que el sujeto pasivo no esté — evidentemente, por no haber sido aún encontrado- y, por lo tanto que, en esta parte, no haya desarrollando alguna función, en la fase del juicio oral, sin embargo, no puede ni siquiera abrirse sin la determinación de un presunto culpable.

En definitiva, podemos decir que estas consideraciones son muy útiles para entender la importancia del derecho a ser informado de la acusación, siendo esto el principal y fundamental presupuesto para que se pueda cumplir y realizar, en primer lugar, el derecho de defensa por parte del imputado/acusado, y, en segundo lugar, para que se pueda llevar a cabo una participación activa del mismo dentro del proceso.

\section{IV.4. EL OBJETO DE LA INFORMACIÓN}

Tal y como establece el art. 24.2 CE «todos tienen derecho [...] a ser informados de la acusación", podía parecer que esta última — la acusación- represente el objeto de la información. 
A pesar de las apariencias y de la posible interpretación literal de este precepto constitucional, tenemos que considerar más amplio el alcance semántico de esta expresión, puesto que la norma no se refiere sólo a la acusación técnica, consagrada en una imputación formal, sino, más bien, en la acusación e imputación material ${ }^{62}$.

Entonces vemos cómo informar sobre la acusación significa, principalmente, comunicar los hechos delictivos que se imputan al inculpado - no cualquier hecho, sino solamente los hechos que se consideran jurídica y penalmente relevantes - así como las normas que se consideran violadas, las posibles consecuencias jurídicas de esta violación y, en general, todos aquellos elementos que serán objeto de debate en el posterior juicio oral ${ }^{63}$.

En este sentido vemos cómo el Tribunal Constitucional ha querido matizar la importancia "a efectos de la defensa del acusado" de la indicación de la calificación jurídica ${ }^{64}$. Efectivamente, tras un atento análisis, resulta claro que la estrategia defensiva puede depender muchísimo de la configuración penal del delito que la acusación ha optado por escoger.

Apreciamos entonces que, si por un lado es pacifico que determinados elementos de hecho tengan que poderse subsumirse dentro de un específico tipo delictivo para que se pueda condenar por él, por otro es necesario que la acusación describa adecuadamente la acusación misma, para permitir un correcto desarrollo del derecho a la defensa.

En este contexto, se ha de indicar otro problema, de no fácil solución, representado por el caso, ciertamente no raro, en el que una sentencia refleja una modificación de algunos de los elementos que han constituido parte de la acusación. Hablamos de la hipótesis que plantea el art. 733 de la LE-

62 A. Planchadell Gargallo, El derecho fundamental a ser informado de la acusación, Ed. Tirant Lo Blanch, Valencia, 1999, p. 100 y ss.; V. FAIRÉn GullLén, ¿Hacia la desaparición definitiva del auto de procesamiento?, RDPc 1993, n. 2, p. 256; T. ARmenTA Deu, Principio..., op. cit., pp. 33 y 34; A. DEl Moral García, El derecho a ser informado de la acusación en el procedimiento abreviado para determinados delitos, Actualidad Penal 1989, n. 13, p. 651.

63 En este sentido, recordamos, entre otras, las SsTC 12/1981, de 10 de abril; 105/1983, de 23 de noviembre; $17 / 1988$, de 16 de febrero; 57/1988, de 1 de marzo y la STS 2329/1997, de 15 de marzo.

64 STC 12/1981, de 10 de abril; 95/1995, de 19 de junio; 225/1997, de 15 de diciembre.

65 Art. 733 LECRIM: «Si juzgando por el resultado de las pruebas entendiere el Tribunal que el hecho justiciable ha sido calificado con manifiesto error, podrá el Presidente emplear la siguiente fórmula: "Sin que sea visto prejuzgar el fallo definitivo sobre la conclusiones de la acusación y la defensa, el Tribunal desea que el Fiscal y los defensores del procesado (o los defensores de las partes cuando fuesen varias) le ilustren acerca de si el hecho justiciable constituye el delito de ... o si existe la circunstancia eximente de responsabilidad a que se refiere el número ... del artículo ... del Código Penal"».

Esta facultad excepcional, que el Tribunal usará con moderación, no se extiende a las causas por delitos que sólo pueden perseguirse a instancia de parte, ni tampoco es aplicable a los errores que hayan podido cometerse en los escritos de calificación, así respecto de la apreciación de las circunstancias atenuantes y agravantes, como en cuanto a la participación de cada uno de los procesados en la ejecución del delito público, que sea materia de juicio. Si el Fiscal o cualquiera de los defensores de las partes indicaren que no están suficientemente preparados para discutir la cuestión propuesta por el Presidente, se suspenderá la sesión hasta el siguiente día. 
$\mathrm{CRIM}^{65}$, en el que, concretamente, se prevé el caso del tribunal que condena alterando la calificación jurídica de los hechos pero no los hechos en sí mismos. La norma únicamente exige el respeto del contradictorio a través de la comunicación de esta modificación de la calificación jurídica antes de llegar a sentencia ${ }^{66}$.

Según el Tribunal Constitucional ${ }^{67}$ para que esta modificación sea legal y no recurrible, el criterio fundamental a tener en consideración es el de la gravedad del delito distinto. En otras palabras, cuando el delito modificado por el que se condena conlleva una sanción de igual o menor gravedad respecto al tipo penal formulado al principio por la acusación —se habla en este caso de "homogeneidad" de los bienes jurídicos o de los intereses protegidos- esta modificación, reflejada en la sentencia, es lícita y posible, siempre que, como hemos dicho, haya sido "conocida" por parte de la defensa.

Con esto, lo que el Tribunal Constitucional quiere poner en evidencia, es que una condena que se funda sobre un título distinto respecto al que ha sido consagrado en el escrito de acusación no se puede poner en relación con el derecho a ser informado de la acusación, sino, más bien, con otras garantías procesales, igualmente tuteladas por el art. 24 de la Constitución, sobre todo, el derecho a la contradicción. Efectivamente, si detenemos nuestra atención sobre el art. 733 LECRIM, y sobre todo sobre el momento de su aplicación natural, vemos que se trata de una fase del proceso ya relativamente madura, en la que la acusación —es decir, la atribución de determinados hechos delictivos, prescindiendo de su calificación jurídica posteriormente modificada- ya ha sido formulada y, se asume, comunicada. Resumiendo, lo que el Tribunal Constitucional exige no es que se vuelva a informar sobre la acusación, sino, más correctamente, que se informe la defensa acerca de la modificación del tipo delictivo por el que se pretende condenar ${ }^{68}$.

Hablar del contenido de la información acerca de la acusación significa determinar, de alguna manera, el alcance mismo de esta información. La Constitución no especifica nada al respecto, pero se entiende que el núcleo de noticias que hay que comunicar a la persona interesada tiene que ser suficiente para que ésta pueda articular su estrategia defensiva.

66 Según parte de la doctrina y de la jurisprudencia se exige, además, que la acusación adopte la nueva calificación jurídica. A. MARTínez ARIETA, La nueva concepción jurisprudencial del principio acusatorio, Ed. Comares, Granada, 1994; J. M. Asencio Mellado, Principio acusatorio y derecho de defensa en el proceso penal, Ed. Trivium, Madrid, 1991.

67 Véase en particular las SsTC 134/1986, de 29 de octubre y 25/1997, de 11 de febrero, en las que el Tribunal Constitucional ante afirma que la sujeción de la condena a la acusación no puede ir tan lejos como para impedir que el órgano judicial modifique la calificación de los hechos enjuiciados en el ámbito de los elementos que han sido o han podido ser objeto de debate contradictorio, y, además, añade que no le compete a él establecer relaciones de homogeneidad entre los tipos penales, sino, más bien, un análisis externo de la razonabilidad del juicio de homogeneidad llevado a cabo por los órganos judiciales.

68 En este sentido, A. De la Oliva Santos, S. Aragoneses Martínez, R. Hinojosa Segovia, J. J. Muerza Esparza y P. Tomé García, Derecho Procesal Penal, Ed. Centro de Estudios Ramós Areces, 1999, p. 566 
Un problema singular relacionado con el objeto de la información, consiste en establecer si ésta tiene que incluir determinados elementos "sensibles", como, por ejemplo, la identidad del acusador ${ }^{69}$.

La natural concisión del texto constitucional no impide una solución del caso, sobre todo si acudimos - a través del art. 10.2 CE- al art. 6 del CEDH, en particular en la parte donde se reconoce al acusado el derecho de "interrogar o hacer interrogar a los testigos que declaren contra él».

Para que este derecho llegue a concretarse parece necesario e imprescindible comunicar a la defensa las fuentes de su acusación, de modo que el acusado pueda eficazmente articular su defensa y, en particular, a través del interrogatorio, provocar que el acusador caiga en contradicción.

A pesar de esto, no tenemos que caer en el error de pensar que cualquier denuncia anónima tiene, necesariamente, que considerarse contraria a los principios consagrados en los arts. $24 \mathrm{CE}$ y $6 \mathrm{CEDH}$, y más claramente, al derecho a ser informado de la acusación ${ }^{70}$, pues frustrar el comienzo de cualquier actividad instructora por no tener un origen definido representaría, por un lado una solución demasiado radical y contraria a los intereses fundamentales de la prevención y represión de los delitos, pero, sobre todo, no encuentra ningún respaldo legislativo, que de otra manera debería ser necesario, a la luz de la gravedad de sus eventuales consecuencias. En este sentido, la LECRIM, en su art. $264^{71}$, establece la obligación de denunciar la perpetración de delitos para todas aquellas personas que hayan tenido conocimiento de los mismos a través de "cualquier medio"; es cierto pues que la ley ampara las hipótesis de investigaciones que tienen comienzo sobre la base de denuncias anónimas.

Es cierto que la identidad del acusador es sólo uno de los elementos que forman objeto de la acusación, pero existen muchos elementos más que, en mano de la acusación, deben ser comunicados al acusado para permitirle un correcto desarrollo de la actividad defensiva. Vemos entonces, que el centro de la cuestión no gira sobre el "Si" sino, más bien, sobre el "cuándo". En otras palabras, así como no se puede cuestionar la necesidad de informar a la defensa de los resultados de la instrucción penal, no se puede exigir, sin embargo, que ésta se vea frustrada por un prematuro levantamiento del secreto de sumario.

Estas consideraciones nos ayudan a introducir otro aspecto fundamental, representado por el momento en el que se debe informar de la acusación.

69 Así F. CaAmaño Domínguez, "Algunas consideraciones sobre...", op. cit., p. 475.

70 Siempre F. CaAmaño Domínguez, "Algunas consideraciones sobre...", op. cit., p. 476.

71 Art. 264 LECRIM: "El que por cualquier medio diferente de los mencionados tuviere conocimiento de la perpetración de algún delito de los que deben perseguirse de oficio, deberá denunciarlo al Ministerio fiscal, al Tribunal competente o al Juez de instrucción o municipal, o funcionario de policia, sin que se entienda obligado por esto a probar los hechos denunciados ni a formalizar querella. El denunciador no contraerá en ningún caso otra responsabilidad que la correspondiente a los delitos que bubiese cometido por medio de la denuncia o con su ocasión.. 


\section{IV.5. EL MOMENTO DE LA INFORMACIÓN}

Al analizar el derecho a ser informado de la acusación hemos hecho, veladamente, referencia a la naturaleza preprocesal de esta garantía. Efectivamente, si elegimos tomar como punto de referencia el momento de incoación del proceso, podemos distinguir entre una información anterior a esta fase, que podríamos definir propiamente "preprocesal" y que se produce en el momento de la detención, y una posterior, "procesal" en un sentido estricto $^{72}$.

Más allá de las definiciones, lo que importa poner en evidencia es la necesidad de que la información llegue al interesado "prontamente". Este adverbio, escogido entre otros, que igualmente podrían valer ${ }^{73}$, necesita una mayor especificación.

En primer lugar, mientras no existen dudas acerca del terminus ad quem de la información, puesto que este derecho permanece vigente a lo largo de toda la duración del proceso, parece más complicado determinar con precisión el terminus a quo, es decir, el momento inicial de la información, pues, como sabemos, la Constitución no adopta ningún criterio cierto ni hace ninguna referencia específica a algún momento concreto ${ }^{74}$.

Diferentes doctrinas han procurado resolver este dilema, en particular podemos citar dos: la de Planchadell Gargallo y Caamaño Domínguez y la de Banacloche Palao.

Según Caamaño Domínguez ${ }^{75}$ y Planchadell Gargallo ${ }^{76}$ para resolver la cuestión es, en primer lugar, necesario interpretar ampliamente la palabra "acusación", en el sentido de toda notitia criminis que se hace llegar al órgano judicial, incluyendo así denuncias o querellas y también atestados policiales o diligencias preliminares ${ }^{77}$. De esta manera, según esta doctrina, el terminus a quo retrocedería al momento de la "imputación", consideración que lleva, por ejemplo, a Planchadell Gargallo a no hablar de derecho a ser informado de la acusación, sino más bien de "derecho a ser informado de la iniciación del proceso penal". Es cierto que retrasar este momento a la apertura

72 Así T. Armenta Deu, Principio..., op. cit., p. 89; y J. M. Asencio Mellado, Principio acusatorio $y \ldots$, op. cit., p. 96.

73 Es cierto que las expresiones utilizadas por la doctrina y la jurisprudencia se acumulan, así por ejemplo, el C.E.D.H., como hemos visto, habla del "más breve plazo posible»; el Tribunal Constitucional —STC 154/1991, de 10 de julio — habla de una acusación que deberá "realizarse con el tiempo suficiente"; según L. M. Díez-PiCAZo Jiménez (Cometarios a la Constitución Española de 1978, tomo III, dirigido por O. Alzaga Villamil, EDERSA, Madrid, 1996, p. 104) la acusación deberá ser "tempestiva".

74 Cabe recordar que en otras ocasiones no hay dudas acerca de aspectos similares como, por ejemplo, en el art. 17, en el que se reconoce el derecho a ser informado de las causas de la detención, en el mismo momento en el que ésta se realiza.

75 F. CaAmaño Domínguez, "Algunas consideraciones sobre...", op. cit., p. 468.

76 A. Planchadell Gargallo, El derecho fundamental..., op. cit., p. 127.

77 En este sentido véanse las SsTC 44/1995, de 22 de marzo; 186/1990, de 15 de noviembre; 128/1993, de 19 de abril. 
del juicio oral, además de hacer inútil cualquier información, frustraría toda actividad defensiva por no dejar margen de tiempo útil para el desarrollo de esta actividad.

Sin embargo, según Banacloche Palao ${ }^{78}$ no se puede frustrar las investigaciones por un exceso garantista que acabe impidiendo la efectividad de la persecución penal. Así, este término inicial no tiene por qué tener un comienzo general y objetivamente establecido. Según esta doctrina el terminus a quo deberá establecerse en función de cada caso concreto, haciendo referencia a un único presupuesto concreto representado por el hecho que la acusación sea suficientemente madura, es decir, fundada sobre indicios racionales de criminalidad.

Así, aunque la información llegue a la defensa en un momento en el que la investigación de la acusación se encuentra ya desarrollada, nada tiene por qué impedir el correcto desarrollo de la función de garantía del derecho a ser informado de la acusación, pues quedaría la posibilidad, para la defensa, de proponer cuantas diligencias estime oportunas y necesarias para el desarrollo de la estrategia defensiva, incluidas la reiteración de las anteriores a dicho conocimiento ${ }^{79}$.

Tal vez sea esta última la opción más oportuna y favorable, debido a la capacidad de conyugar la efectividad de la persecución penal con el pleno desarrollo de las garantías procesales, quizás, eso sí, a costas de la rapidez del juicio.

Desde luego, un problema del todo singular, se plantea en el caso del juicio de faltas, en el que, como es sabido, no hay acusación hasta la vista ${ }^{80}$ y en el que, por lo tanto, se pueden ver frustradas las exigencias más elementales de la defensa ${ }^{81}$. Una solución a este particular problema ha sido ofrecida por el Tribunal Constitucional que, en su STC 135/1997, recuerda que "la citación del denunciado para comparecer en juicio constituye el único medio que se le ofrece para conocer la existencia del proceso y, por ello, para preservar el mandato constitucional según el cual nadie puede ser condenado sin conocer previamente la acusación contra él formulada" así que "siempre que conste con certeza la citación del denunciado y no baya datos que permitan concluir que el mismo conoció por otros medios la existencia del proceso, el Juez de Instrucción ba de considerar constitucionalmente obligada la suspensión del juicio por ser la declaración de aquél la única forma de garantizar el derecho a ser informado de la acusación contra él formulada”.

78 J. Banacloche Palao, "El derecho a ser informado de la acusación, a no declarar contra uno mismo y a no confesarse culpable", en Cuadernos de Derecho Público, n. 10, 2000, p. 191.

79 En este sentido, véase la STC 220/1998, de 16 de noviembre.

80 Generalmente, en estos casos, se habla de "acusación implícita o tácita".

81 Es muy interesante, a este propósito, las SsTC 182/1991, de 30 de septiembre, y 230/1997, de 16 de febrero, por qué reconoce la violación no ya del derecho ser informado de la acusación, sino, más genéricamente, de un proceso con todas las garantías. 


\section{CONCLUSIONES}

Concluimos nuestro estudio sobre algunas perspectivas del derecho a ser informado de la acusación, y es en estos momentos cuando nuestro pensamiento vaga por todos aquellos aspectos que, por necesidad y economía del discurso, hemos dejado atrás. Tomamos, así, en esta sede, el compromiso de volver a tratar de ellos en nuestras futuras fatigas investigadoras.

Es cierto que la importancia fundamental del derecho a la tutela judicial efectiva, tanto en el ámbito del Convenio Europeo de Derechos Humanos, como en otro a nosotros más cercano - el de la Constitución y de su art. 24-, descansa concretamente en la capacidad de imponer un amplio sistema de garantías dirigidas a la realización del máximo objetivo de la Justicia: la seguridad jurídica.

No sólo ofreciendo a los ciudadanos la posibilidad de acceder a las salas de justicia para conseguir la satisfacción de sus propias pretensiones jurídicas, sino, sobre todo, al imponer la protección y respeto de todo un complejo de garantías preestablecido y dirigido a hacer de cualquier procedimiento judicial un proceso realmente equitativo y justo.

Es cierto que cualquier proceso que aspire a ser considerado justo y equitativo no puede ni siquiera empezar sin garantizar el derecho a ser informado de la acusación.

De esta manera, hemos visto cómo la obligación de proporcionar al acusado de un delito todo el conocimiento necesario - elementos jurídicos o fácticos- acerca de su acusación representa un presupuesto fundamental del derecho a la tutela judicial efectiva.

Así pues, este estudio ha querido tratar sólo un aspecto concreto y delimitado del más amplio derecho consagrado en el art. 6 del C.E.D.H. y 24 CE, con el fin de hacer evidente, una vez más, la vastedad y la importancia de este derecho fundamental.

TITLE: The right to be informed of the accusation into the European Court on Human Rights and the Spanish Constitutional Court case law.

ABSTRACT: The spanish Constitution art. 24 establishes that "All persons have the right to obtain effective protection from the judges and the courts [...] to be informed of the charges brought against them..." At the same time, the European Convention on Human Rights art. 6.3.a) establishes that "Everyone charged with a criminal offence has the following minimum rights: to be informed promptly, in a language which be understands and in detail, of the nature and cause of the accusation against him.. This article deals with this aspect of the fair trial, it means, with the right to be informed of the accusation, carrying out a comparison between recent spanish and european case law on this issue.

RESUMEN: El art. 24 de la Constitución española establece que "Todas las personas tienen derecho a obtener la tutela efectiva de los que jueces y tribunales [...] a ser in- 
formados de la acusación formulada contra ellos". Asimismo, el art. 6.3.a) del Convenio Europeo de Derechos humanos establece que "Todo acusado tiene, como mínimo, los siguientes derechos: a ser informado, en el más breve plazo, en una lengua que comprenda y detalladamente, de la naturaleza y de la causa de la acusación formulada contra él. Este artículo trata de este aspecto del proceso justo, es decir, del derecho a ser informado de la acusación, desarrollando una comparación entre la jurisprudencia constitucional española y la europea sobre este mismo argumento.

KEY WORDS: Trial. Fair. Informated. Accusation. ECHR. Case law.

Palabras Clave: Proceso. Justo. Informado. Acusación. CEDH. Jurisprudencia. 